\title{
Preliminary Study: Self-Regulated Learning Procedure
}

\author{
Shafizza Sahdan ${ }^{*}$, Alias Masek ${ }^{2}$, Noor Atikah Zainal Abidin ${ }^{3}$, Juliati Jusoh $^{4}$ \\ 1,2,3 Faculty of Technical and Vocational Education, Universiti Tun Hussein Onn Malaysia, 86400 Batu Pahat, Johor. \\ ${ }^{4}$ Department of Commerce, Polytechnic Sultan Haji Ahmad Shah, Semambu, 25350 Kuantan, Pahang.
}

\begin{abstract}
Self-regulated learning (SRL) is widely adopted by various educational institutions all over the world. A simple guideline is important and essential for the successful implementation of SRL that yields good results. Hence, a procedure and lesson plan of SRL for the subject of Principles of Management are developed and tested in a preliminary study. The objective of the preliminary study is to determine the reliability of the instruments so that the implementation procedure and lesson plan for the real study can be executed smoothly. This study was conducted for a cycle of SRL designed procedure. ANCOVA was used to analyse the effects of the procedure and lesson plan in relation to students' motivation, metacognitive awareness and academic achievement. Based on the results of the preliminary study, the items reliability index using alpha cronbach was 0.92 , indicated that the questionnaire was good and effective. Each variable was significantly different, indicated that the procedure and lesson plan have positive effects on motivation, metacognition, and academic achievement. In conclusion, the procedure and lesson plan of Principles of Management developed are ready for an actual study.
\end{abstract}

\section{Introduction}

Education is a key to success in life. Education is started with a good learning strategy. A good strategy employed in learning can influence the academic success of students. Self-regulated learning (SRL) is one of the best strategies available thus far that focuses on developing students to become independent learners. With a systematic procedure of SRL and a combination of a variety of SRL activities in the lesson plan, there is a high probability that a student may succeed in their learning. SRL can be defined as an effective rule and strategy implemented in students' learning process in order to achieve their own goals [1].

SRL strategies have a very good and positive effect on individuals, especially for students who are undergoing the learning process. This statement is supported by the findings of [2], which state that students' achievement increases when they apply SRL in the classroom. The author [3] also said that students can increase their skills in the future when they receive feedback and comments from the lecturers to improve their learning strategies. The mastery learning, cooperative learning and computer-based learning for each student nowadays can be implemented using the SRL strategies.

Although the literature suggests that the implementation of SRL promises several advantages, most students and lecturers are sceptical about adopting SRL in teaching and learning. SRL is a more suitable learning strategy for students who are eager to search for advice and information on their own initiative [4]. This type of learning attitude really helps them to acquire knowledge more quickly and effectively. The students tend to look out for a more positive environment conducive to learning instead of staying in a negative environment [5].

According to [6], SRL is strongly related to motivation of a student, as motivation is one of the important factors in SRL. Hence, when students implement SRL as a tool, they will automatically be motivated to embrace learning. As the level of motivation increases, the level of academic achievement of the students also increases. Metacognition of students increases when they apply SRL. According to [7], students who apply SRL can think more creatively and generate more ideas based on their learning outcomes. In a sentence, SRL has a very good impact on students, and teachers should implement the strategy using the right procedure so that students can produce good outcomes of learning.

SRL undergoes three phases of activities, which are forethought, performance and self-reflection [8]. These are the main phases a student will go through when the SRL strategy is implemented as a learning approach. In this study, a combination of activities based on the SRL strategy is used to create a new procedure with a complete range of activities in each phase. The development of the procedure and lesson plan is based on three sources, namely the literature review, model and theories; course learning outcomes and expert panel from SRL; and Principles of Management. The development of the procedure and lesson plan of SRL is based on Kemp Model; it is used as a base for the instructional design.

* Corresponding author:hb140176@siswa.uthm.edu.my 
The procedure implemented in the lesson plan will be tested in the teaching and learning process for the Principles of Management subject. Before the actual experiment is conducted, a preliminary study was carried out. Hence, the aim of this paper is to discuss the results of the preliminary study that was conducted before the real experiment is carried out. The first section outlines the objective of the preliminary study, the second section touches on the methodology used, the third section describes the overall results and the fourth section contains the discussions. Lastly, the conclusion of this paper is presented.

\section{Objectives}

The preliminary study was conducted in order to ascertain the effects of the procedure and the lesson plan on the students who are studying the subject of Principles of Management, before the real experiment is conducted. This preliminary study is necessary to ensure that the procedure in the real experiment will run smoothly according to the plan. It is also important to test the validity of the instruments used in this study, and find out if they are suitable for the study. The reliability of the instruments was measured before they are used in the real experiment. The results from the preliminary study were used to upgrade and improve the procedure and lesson plan that had been developed.

\section{Methodologies}

A one-week cycle of SRL procedure was conducted to run the preliminary study. The procedure of this study was the same as that for the real experiment. This is to ensure that the environment for the real experiment is properly developed. An analysis of covariance (ANCOVA) was used in order to find out the effects of SRL on motivation, metacognitive awareness, and the academic achievement of the students. Two main instruments were involved in this study. The first is a questionnaire that comprises two sections, namely motivation and metacognitive awareness. The second is a short test used to measure the students' academic achievement before and after the application of the procedure and lesson plan of Principles of Management.

\subsection{Experimental procedure}

The preliminary study involved two groups of students, namely the experiment group and the control group. A carefully designed SRL procedure and a lesson plan were used as the treatment for the experiment group within the context of Principles of Management subject. In this case, the selected class of this study was not informed of the research conducted to avoid bias. Similarly, the control group was set up to undergo the usual teaching and learning process using the traditional approach. Before the class started, a pre-test questionnaire and pre-test quiz were distributed to measure the students' existing knowledge. After one cycle of SRL procedure that consisted of two classes, a post-test questionnaire and post-test quiz were distributed to measure and monitor the difference that occurred, for both the experiment and control groups. The roles of lecturers are important in this study as the lecturers act as facilitators who guide students in following the procedure and lesson plan developed.

\section{Results}

Each variable was tested, and the results are explained. Before the analysis of the preliminary study was conducted, reliability of instrument was checked and then the ANCOVA analysis was conducted. The ANCOVA analysis shows that there is a difference in the results of the experiment and control groups for the score of each variable in relation to academic achievement, motivation and metacognitive awareness. The analysis results are used to interpret whether the procedure and lesson plan of Principles of Management have any effect on the students' academic achievement, motivation and metacognition.

\subsection{Pilot Study}

A pilot test was conducted on the instrument to ensure suitability of the questionnaire developed and modified. Before the questionnaire can be used, the questionnaire was checked by the supervisor and a few experts to ensure items/construct validity. Before the preliminary study was conducted, the questionnaire underwent backto-back translation as the original questionnaire is in English. The translation was done in two processes: from English to Malay, and then Malay to English; through this procedure, it is quite certain the translations are accurate and the instrument can be used to achieve the objectives. The test used to measure the academic achievement of students also underwent a few processes. First, the test was developed based on the findings of the past year papers. Then discussions were held with a panel of experts who teach the subject of Principles of Management. These discussions are important to know the students' basic knowledge and mind-set so that they can understand the test developed. The roles of the expert panel are to verify the validity of the test if it suits the students.

The reliability of the questionnaire was measured using the alpha value. When the alpha value is larger than 0.60 , the reliability of the instrument is acceptable, and it can be used in the real-world environment [9]. The results of the pilot test show that the reliability for the overall constructs is $0.921(\alpha>0.60)$, which indicates that the instrument is very good and effective to be used. The alpha values of the constructs are 0.828 and 0.929 for metacognitive awareness and motivation respectively. The summary of each construct is shown in Table 1. 
Table 1. Alpha Cronbach

\begin{tabular}{|c|c|}
\hline Construct & Alpha cronbach \\
\hline Metacognitive Awareness & 0.828 \\
\hline Motivation & 0.929 \\
\hline Overall & 0.921 \\
\hline
\end{tabular}

\subsection{Effects of SRL Lesson Plan on Students' Academic Achievement}

An analysis of covariance (ANCOVA) was used to investigate the effects of the variables; the post-test results reflect that the experiment group attained a higher level of academic achievement than the control group. The differences in the means and standard deviations for the both groups are shown in Table 2. The homogeneity of variances is not violated. This is due to the cell sizes of this study that are not similar, which are 21 and 34 . The results show that there are significant differences between the experiment group and control group in the post-tests, $F(1,51)=.5 .85, p=.019$, partial eta ${ }^{2}=.103$; the pre-tests were controlled. Table 3 shows the means and standard deviations of the post-test achievements for both groups in relation to the subject of Principles of Management; the pre-tests of Principles of Management were controlled.

Table 2. Adjusted and unadjusted group mean (experiment and control) and variability for post-test using pre-test as a covariate.

\begin{tabular}{|lccccc|}
\hline \multirow{2}{*}{ Group } & \multirow{2}{*}{$\mathbf{N}$} & \multicolumn{2}{c}{ Unadjusted } & \multicolumn{2}{c|}{ Adjusted } \\
\cline { 3 - 6 } & & M & SD & M & SE \\
\hline Experiment & 21 & 46.19 & 11.61 & 45.92 & 3.1 \\
\hline Control & 34 & 44.41 & 17.44 & 43.52 & 2.4 \\
\hline
\end{tabular}

Table 3. Analysis of covariance for post-test as a function of group (experiment and control), using pre-test as a covariate

\begin{tabular}{|lccccc|}
\hline Source & $\boldsymbol{d} \boldsymbol{f}$ & $\boldsymbol{S S}$ & $\boldsymbol{M S}$ & $\boldsymbol{F}$ & $\boldsymbol{p}$ \\
\hline Pre test & 1 & 530.83 & 530.83 & 2.74 & .104 \\
Group* & 1 & 1133.30 & 1133.30 & 5.85 & .019 \\
$\begin{array}{l}\text { Pre-test } \\
\text { Error }\end{array}$ & 51 & 9882.35 & 193.77 & & \\
Total & 55 & 124600.00 & & & \\
$\begin{array}{l}\text { Corrected } \\
\text { total }\end{array}$ & 54 & 12774.55 & & & \\
\hline
\end{tabular}

\subsection{Effects of SRL Lesson Plan on Students' Metacognition}

The results indicate that there are differences in the means for both experiment and control groups. The score differences of metacognitive awareness are shown in Table 4 . The assumption of homogeneity of variance is violated due to the cell sizes that are dissimilar (21 and 34). Results indicate that after the controlling for the pre-test metacognition, there are significant differences between the groups (experiment and control) in the posttest metacognition, $F(1,51)=.15 .30, p=.000$, partial eta ${ }^{2}$ $=.231$. Table 5 presents the post-test means and standard deviations of both groups for metacognitive awareness; the pre-test metacognitive awareness was controlled.

Table 4. Adjusted and unadjusted group mean (experiment and control) and variability for post-metacognitive using premetacognitive as a covariate.

\begin{tabular}{|lccccc|}
\hline \multirow{2}{*}{ Group } & \multirow{2}{*}{ N } & \multicolumn{2}{c}{ Unadjusted } & \multicolumn{2}{c|}{ Adjusted } \\
\cline { 3 - 6 } & & M & SD & M & SE \\
\hline Experiment & 21 & 42.38 & 6.18 & 42.47 & 1.03 \\
\hline Control & 34 & 43.06 & 5.83 & 43.42 & .80 \\
\hline
\end{tabular}

Table 5. Analysis of covariance for post- metacognitive as a function of group (experiment and control), using premetacognitive as a covariate

\begin{tabular}{|lccccc|}
\hline \multicolumn{1}{|c}{ Source } & $\boldsymbol{d} \boldsymbol{f}$ & $\boldsymbol{S S}$ & $\boldsymbol{M S}$ & $\boldsymbol{F}$ & $\boldsymbol{p}$ \\
\hline Post test & 1 & 261.24 & 261.24 & 11.95 & .001 \\
Group* & 1 & 334.57 & 334.57 & 15.30 & .000 \\
Metacognitive & & & & & \\
Error & 51 & 1115.02 & 21.86 & & \\
Total & 55 & 102642.00 & & & \\
Corrected Total & 54 & 1890.80 & & & \\
\hline
\end{tabular}

\subsection{Effects of SRL Lesson Plan on Students' Motivation}

An analysis of covariance (ANCOVA) was used to investigate the effects of the variables; the post-test results reflect that the experiment group attain a higher level of academic achievement than the control group. The differences in means and standard deviations for both groups are shown in Table 6. The assumption of homogeneity of variance is violated. It is because the cell sizes are dissimilar (21 and 34); this violation does not present an issue. After the pre-test for motivation was controlled, there are significant differences between the groups (experiment and control) in the post-test results, $F(1,51)=4.49, p=.039$, partial eta ${ }^{2}=.08$. Table 7 presents the means and standard deviations of the post-test motivation for the groups (experiment and control); the pre-test motivation was controlled.

Table 6. Adjusted and unadjusted group mean (experiment and control) and variability for post-test motivation using pre-test motivation as a covariate.

\begin{tabular}{|lccccc|}
\hline \multirow{2}{*}{ Group } & \multirow{2}{*}{$\mathbf{N}$} & \multicolumn{2}{c}{ Unadjusted } & \multicolumn{2}{c|}{ Adjusted } \\
\cline { 3 - 6 } & & $\mathbf{M}$ & SD & M & SE \\
\hline Experiment & 21 & 5.40 & .78 & 5.33 & .14 \\
\hline Control & 34 & 5.16 & .76 & 5.26 & .10 \\
\hline
\end{tabular}

Table 7. Analysis of covariance for post- motivation as a function of group (experiment and control), using premotivation as a covariate

\begin{tabular}{|lccccc|}
\hline Source & $\boldsymbol{d} \boldsymbol{f}$ & $\boldsymbol{S S}$ & $\boldsymbol{M S}$ & $\boldsymbol{F}$ & $\boldsymbol{p}$ \\
\hline Post test & 1 & 7.28 & 7.28 & 20.36 & .000 \\
Group*Motivation & 1 & 1.61 & 1.61 & 4.49 & .039 \\
Error & 51 & 18.234 & 0.36 & & \\
Total & 55 & 1547.19 & & & \\
Corrected Total & 54 & 32.01 & & & \\
\hline
\end{tabular}




\section{Discussions}

In this study, several student-centred learning activities are involved in the SRL strategy. Those activities help students to acquire higher-quality knowledge from their learning process. In this study, the SRL procedure and lesson plan guide students to learn more effectively in the theoretical subjects, although they are boring and hard to learn. Hence, a procedure and lesson plan of SRL are developed and implemented to improve the quality of students in the future. The effects of the SRL procedure on motivation, metacognition, and academic achievement of students are discussed.

In this study, the results indicate that there is a significant difference between the academic achievement of the experiment group and that of the control group. Although the treatment was carried out within a very short period, the higher resultant test scores are a sign that students' achievement was improving. These findings are in line with the results from [10], which indicate that student receive a higher score if they were exposed to the adoption of SRL in important assignments. The findings from [11] state that SRL have a positive relationship with the academic performance of a student. Students who can improve their academic achievement can train their cognitive faculty to think more creatively. Students need a good and effective strategy to use advanced technology nowadays in order to achieve and improve their own performance in the future [12]. A student who has a good strategy will produce academic performance; on the other hand, a student may not show much improvement if he or she depends fully on an advanced technology but does not know how to use it effectively in the learning process. Based on the cognitive theory, when students think creatively, they can easily apply the theoretical principles to solve practical problems in the real life, and this can improve the quality of students [13].

In the context of metacognitive awareness, the results show that the experimental group has outperformed the control group in terms of scores. Metacognition indicates how students think, create and manoeuvre the information they have acquired from the learning process; the various forms of information and important facts can be used to answer questions in the examination. This thinking style is in line with the constructivism theory: students learn from their past, for example learning in class, and create new knowledge based on their own understanding [14]. This learning theory focuses on the thinking ability of students, rather than knowledge that is totally from the lecturer. This theory is in line with the objectives of the SRL strategy; it focuses on the student-centred learning. The students are the main character in the learning process and lecturers play the role of facilitator.

The findings are supported by the statement from [15]; when student are exposed to the SRL strategies, they will be trained to think more creatively in their learning process. The results from [7] show that the metacognition of students improve when they apply the SRL strategies, and they can use different types of strategies that suit them best. Peer assessment is one of the strategies that can be employed to evaluate the metacognition of a new-generation student; a more sophisticated and effective strategy is needed to evaluate a new breed of students today [16]. In peer assessment, students can train their metacognition as they act as an evaluator to assess the performance of their friends. Hence, they will automatically think broadly and effectively as they need to comment on their friends' work. This will help them to produce more knowledge for their friends and for themselves. Their metacognitive faculty will be used frequently, and their thinking skills will be sharpened; this will result in an increase in performance in the future.

The post-test results show that there was a statistically significant difference on students' motivation between the two groups (experiment and control). Students who have a high degree of motivation tend to take initiative to search for a better environment. This attitude is in line with the Gagne learning theory, whereby students try to search for new strategies in order to acquire the needed knowledge [17]. The findings of this study were also in line with the result from Yoon [18], which state that self-confidence of a student increases when he or she applies SRL. When selfconfidence increases, students tend to be more motivated and have a greater desire to learn more new things. Lastly, they will be willing to learn harder subjects in order to gain more knowledge. These findings are supported by [5]: students are more energetic and motivated when they adopt and apply the SRL strategies. In contrast, there are previous studies that do not support the findings; the study results from [19] say that when students apply SRL, they feel that they do not receive the full attention from the lecturers as some of them need a lot of guidance from the lecturers. Hence, they tend to lose control of themselves and are unable to focus in the classroom. Although there are some shortcomings in the application of SRL, generally the adoption of SRL has implied on the positive changes on students' academic performance.

In summary, SRL has positive impacts on students' academic achievement, metacognition and motivation. Hence, for future research, the results obtained from this study can be used to upgrade and modify the procedure and lesson plan of Principles of Management. This will facilitate the smooth running of actual studies without any major difficulties and help future researchers to replicate the similar study to other context of research.

\section{Conclusions}

The SRL procedure and lesson plan within the Principles of Management subject have been carefully designed. The study has resulted an encouraging improvement on students' achievement, metacognition, and motivation. These preliminary study findings provide a proper framework for carrying out the actual study, which has shed light on the benefits of SRL. In addition, this study has yielded very encouraging findings that are applicable 
to students' learning process to attain a higher level of academic performance.

This research is supported by a scholarship awarded by the Malaysian Ministry of Higher Education (Mybrain15) and Universiti Tun Hussein Onn Malaysia.

\section{References}

1. J. L. Nietfeld, L. R. Shores, K. F. Hoffmann, Self-regulation and gender within a game-based learning environment. Journal of Educational Psychology, 106, 961-973 (2014)

2. M. Leidinger, F. Perels, Training SelfRegulated Learning in the Classroom: Development and Evaluation of Learning Materials to Train Self-Regulated Learning during RegularMathematics Lessons at Primary School. Education Research International. Retrieved on Jun 12, 2014 from doi:10.1155/2012/735790 (2012)

3. J. Hattie, Visible learning: A synthesis of over 800 meta-analyses relating to achievement. New York: Routledge. (2009)

4. G. Clarebout, H. Horz, W. Schnotz, The relations between self-regulation and the embedding of support in learning environments. Educational Technology Research and Development, 58(5), 573-587(2010)

5. A.S. Labuhn, B.J. Zimmerman, M. Hasselhorn, Enhancing students' self-regulation and mathematics performance: The influence of feedback and self-evaluative standards. Metacognition and Learning, 5 (2), 173194(2010)

6. M.H. Mahmoodi, B. Kalantari, R. Ghaslani, Self-regulated learning (SRL), motivation and academic achievement of Iranian EFL learners. Procedia - Social and Behavioral Sciences, 1062-1068 (2014)

7. K.D.Y. Campbell, The Effects Of SelfRegulated Learning On Community College Students 'Metacognition And Achievement In Developmental Math Courses. Old Dominion University: Tesis PhD (2013)

8. B.J. Zimmerman, Attaining self-regulation: a social cognitive perspective. In M. Boekaerts, P. R. Pintrich, \& M. Zeidner (Eds.), Handbook of self- regulation.San Diego: CA: Academic Press (2004)

9. Y.P. Chua, Kaedah penyelidikan (Kaedah dan Statistik Penyelidikan). $2^{\text {nd }}$. ed. Malaysia: McGraw-Hill Education. (2011)

10. J.S. Rolf, L. Scharff, T. Hodge, Does “thinking about thinking" impact completion rates of preclass assignments? Paper presented at the Joint
Mathematics Meetings, Boston, January 4.(2012)

11. N.A. Bakar, A. Shuaibu, R.A. Bakar, Correlation of Self-Regulated Learning and Academic Achievement among Universiti Sultan Zainal Abidin (UniSZA) Undergraduate Students. International Journal of Academic Research in Business and Social Sciences, 7(4), 254-268 (2017)

12. S.B. Sahdan, N.A.B.Z. Abidin. Self-regulated learning: A literature review for 21st century learning technology. Advanced Science Letters, 23 (3), 912 - 915 (2017)

13. J. Piaget, Equilibration of cognitive structure. New York: Viking Press. (1970)

14. M. Briner, What is Constructivism?. University of Colorado : Denver School of Education (1999)

15. J.A. Greene, C.M. Bolick, J. Robertson, Fostering historical knowledge and thinking skills using hypermedia learning environments: The role of self- regulated learning. Computers \& Education. 54. 230-243 (2010)

16. N.A.B.Z. Abidin, S.B. Sahdan. Peer assessment : A challenge in the new generation. Advanced Science Letters, 23 (3), 908 - 911 (2017)

17. R.M. Gagne, The Conditions of Learning and Theory of Instruction. 4th ed. New York : Holt, Rinehart \& Winston. (1985)

18. T. Yoon, Are you digitized? Ways to provide motivation for ELLs using digital storytelling. International. Journal of Research Studies in Educational Technology, 2(1), 25-34. (2012)

19. A. Barrus, Does Self-Regulated Learning-Skills Training Improve High-School Students' SelfRegulation, Math Achievement, and Motivation While Using an Intelligent Tutor?.Arizona State University:Tesis Ph.D (2013) 